\section{ECCOMAS}

\section{Proceedia}

\title{
COMPARISON OF 1D EQUIVALENT-LINEAR AND NONLINEAR SEISMIC SITE RESPONSES IN DEEP SEDIMENT LAYERS
}

\author{
Zhu Jiao ${ }^{1}$, Chen Guoxing ${ }^{1}$, and Zhao Kai ${ }^{1}$ \\ ${ }^{1}$ Institute of Geotechnical Engineering, Nanjing Tech University \\ Nanjing 210009, China \\ e-mail: zhujiao90@163.com, gxchen@njtech.edu.cn, zhaokaiseu@aliyun.com
}

Keywords: Deep Sediment Layers, Seismic Site Response, Equivalent Linear, Nonlinear, Ground Motion Parameters.

\begin{abstract}
A reasonable description of soil hysteretic constitutive relation has a significant impact on the evaluation of design ground motion parameters. These parameters play an important role in predicting seismic damage and taking further effective anti-seismic measures. In this study, based on the 200m-deep-borehole profiles in Suzhou region (China), the 1-D seismic site responses are compared by two analysis methods. One is an equivalent linear analysis (ELA) modeling in frequency domain, the other is a nonlinear analysis (NLA) using a multi-degree-of-freedom, lumped mass model in term of the modified Matasovic constitutive modeling in time domain. The effects of bedrock motion characteristics (amplitude, frequency content and duration) on the predictions from the two site response analyses in deep sediment layers have also been analyzed. Using the results from a broad range of bedrock motions, we can find the difference between the two site response analyses in different strain levels. Specifically, the surface peak ground acceleration (PGA) calculated by ELA increases monotonically as the PGA of bedrock motion increases. However, the surface PGA calculated by NLA first increases rapidly and then decreases gradually or keeps constant. Moreover, the surface acceleration response spectra (Sa) for short periods computed using ELA and NLA are significantly different. The high-frequency contents of bedrock motions exhibit obvious filtering in ELA while the high-frequency contents in NLA first magnify and then attenuate as the PGA of bedrock motion increases. In addition, for the medium or strong bedrock motions, the surface ground motion duration is not only related to bedrock motion characteristics, but also closely related to the cyclic behavior of nonlinear soil medium. The influence of bedrock motion intensity on the duration prolongation of surface ground motion can be reasonably evaluated using NLA.
\end{abstract}

(C) 2017 The Authors. Published by Eccomas Proceedia.

Peer-review under responsibility of the organizing committee of COMPDYN 2017. doi: $10.7712 / 120117.5669 .16905$ 


\section{INTRODUCTION}

Many site investigations and theoretical researches indicate that local site conditions have a profound influence on surface ground motions and seismic damage distribution [1-3]. Reliable predictions of seismic site response and design ground motion parameters play an important role in predicting seismic damage and taking further effective anti-seismic measures. The propagation of seismic waves through soil deposits depends on the intensity and frequency content of input ground motions, the seismic wave dispersion and absorption due to soil deposits and cyclic soil constitutive model. The stress-strain relationship of soil under cyclic loading is nonlinear, hysteretic and deformation cumulative. A reasonable description of the dynamic behavior of soil is vital for improving the accuracy of site response analysis.

Based on a large amount of experimental results, Seed and Idriss [4] first found that large strain in soil induced by strong earthquakes was the major factor leading to nonlinear effects of soils, which draw extensive attention to nonlinear soil behavior in the field of geotechnical engineering $[5,6]$. Furthermore, seismic damage investigation records of destructive earthquake events such as the $1985 M_{\mathrm{s}} 8.1$ Mexico earthquake, $1989 M_{\mathrm{s}}$ 7.1 Loma Prieta earthquake, $1995 M_{\mathrm{s}} 7.2$ Kobe earthquake in Japan, and 1999 Chi-Chi earthquake in Taiwan also showed remarkable soil nonlinearity. Based on comparison of site response analyses performed by the equivalent linear analysis (SHAKE) and nonlinear (DEEPSOIL and LS-DYNA) analysis methods, Bolisetti et al. [7] found there were significant differences between predictions from the two analysis methods especially for large strains and higher frequencies; the equivalent linear method is unable to reproduce the high frequency acceleration response, resulting in almost constant spectral accelerations in the short period range. Kaklamanos et al. [8] compared the recorded ground motions of vertical seismometer arrays in Japan with the predictions from corresponding linear, equivalent linear and nonlinear site response models to obtain the strain levels at which the models break down respectively. When the peak shear strains were $0.01 \%-0.1 \%$, the linear site response models failed to accurately predict shortperiod ground motions; when the peak shear strains were greater than $0.05 \%$, nonlinear models exhibited a closer prediction to record data than equivalent linear models.

The equivalent linear model, due to its simplicity and low calculation effort, is the most frequently employed model in engineering practice to approximate nonlinear soil behavior. However, the comparisons of predictions from equivalent linear model with recorded data in vertical arrays demonstrate that, during strong earthquakes, the equivalent linear site response analyses filter out high frequency components of the input motion and almost underestimate the surface peak ground acceleration. Therefore, in this study, based on two typical deep borehole profiles in Suzhou region, the comparisons of 1D equivalent linear and nonlinear seismic site responses are performed within the industry-standard site response program DEEPSOIL, in order to gain insight into the effects of analysis methods on seismic site responses in deep sediment layers.

\section{ENGINEERING GEOLOGICAL CHARACTERISTICS}

Suzhou is located at the southern margin of the Yangtze river delta in china, and is covered by extensive soft clayey soil, saturated silt and silty fine sand belonging to the sedimentary of marine and alluvial lacustrine facies. Deep overburden layers exist in this region, and the general strata are characterized as multi-sedimentary rhythms. Two typical borehole profiles (profile No. 1 and 2), with the overburden thickness over $200 \mathrm{~m}$, as shown in Figure 1, are selected to perform seismic site responses. According to the China Code for Seismic Design of Buildings GB50011-2010 [9], both the sites belong to the III category. The sediment for- 
mation is characterized as alternate deposition of fluvial, lacustrine and marine facies. The typical deposits in Suzhou region are fill, silty clay, silty sand, clay and silty fine sand.

The natural frequency of deposit is closely related to the shear wave velocity of soil [10]. Thus, it is necessary to use the measured shear wave velocities at different depths of the two profiles. Due to the limitation of test condition, the depth of measured shear wave velocity for profile No. 2 is only $167 \mathrm{~m}$. The shear wave velocities of soil at deeper depths are obtained by extrapolating the fitting curve of shear wave velocities with depth. Figure 1 shows the soil distribution characteristics and corresponding shear wave velocities for borehole profile No. 1 and 2.
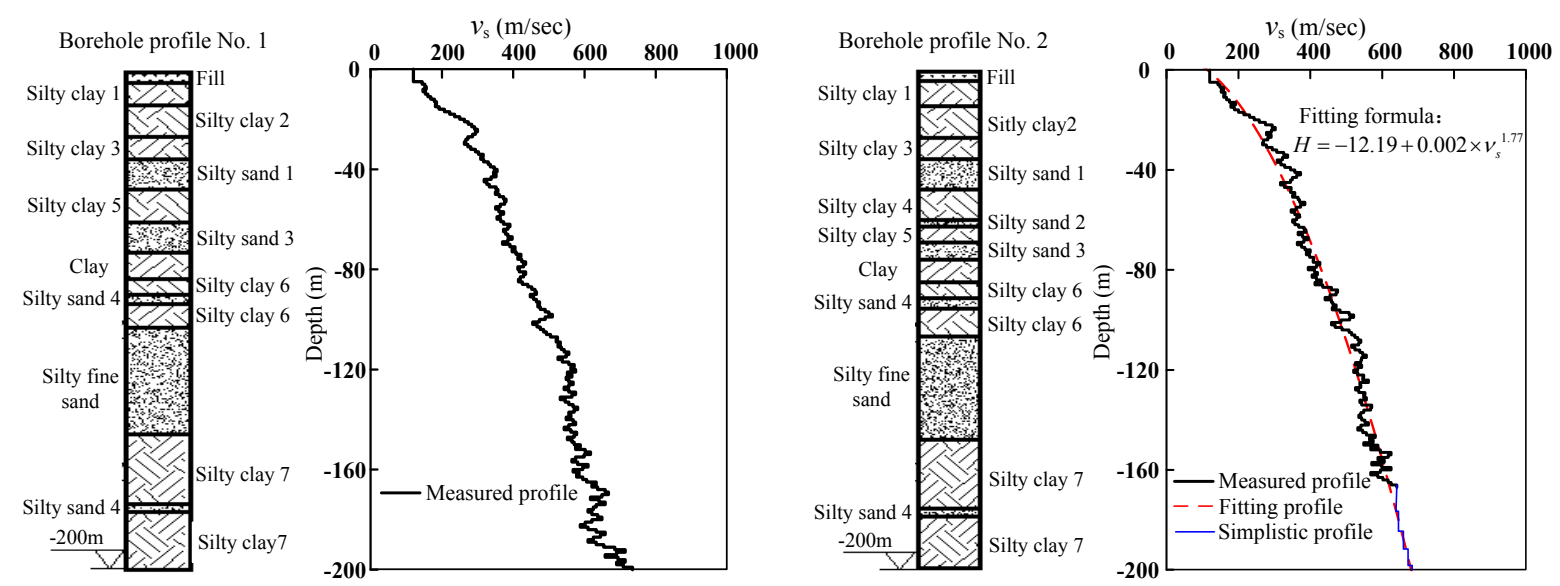

Figure 1: Soil profiles and corresponding shear wave velocity profiles used in the analysis

\section{NONLINEAR CYCLIC BEHAVIORS OF SOILS}

The accuracy of predicted surface ground motions depends on the rationality of the soil hysteretic constitutive relation and the corresponding parameters. The equivalent linear method implemented in DEEPSOIL is similar to that in SHAKE [11], in which the seismic site response is simplified as the one-dimensional wave problem of vertical incident $S$ wave in horizontally layered soil deposit. The equivalent linear viscoelastic model is employed to approximate nonlinear soil behavior, which is not only stable in numerical calculation, but also can consider frequency dependent characteristics such as damping due to the scattering of waves and surface wave propagation, and perform a deconvolution analysis. The layer properties in this method are adjusted through an iterative process involving a series of linear analyses. The linear analysis is first performed using the strain dependent shear modulus and damping obtained directly from the laboratory tests, and the iterations are continued until the calculated shear strains match within a pre-defined tolerance. The equivalent linear method can generally reflect the nonlinear and hysteresis of the dynamic stress-strain relationship of soil. In nonlinear analysis implemented in DEEPSOIL, the geologic column is discretized into individual layers using multi-degree-of freedom lumped parameter model. Each individual layer is represented by a corresponding mass, non-linear spring, and dashpot for viscous damping. Lumping half the mass of each of two consecutive layers at their common boundary forms the mass matrix. The stiffness matrix is updated at each time increment to incorporate nonlinearity of the soil. Hashash et al. (2016) incorporate the nonlinear pressure dependent cyclic soil model in DEEPSOIL. The model is an extension of the modified hyperbolic model developed by Matasovic, and accounts for the influence of confining pressure on strain dependent modulus and damping of soil. The extended Masing criteria define unloadingreloading criteria and behavior under irregular loading conditions. The backbone curve for the model is described by the following equation [11]: 


$$
\tau=\frac{G_{m o} \gamma}{1+\beta\left(\frac{\gamma}{\gamma_{r}}\right)^{s}}
$$

Where

$$
\gamma_{r}=\gamma_{r e f}\left(\frac{\sigma^{\prime}}{\sigma_{r e f}}\right)^{b}
$$

Where $\tau$ is the shear stress; $\gamma$ is the shear strain; $\beta$ and $s$ are dimensionless parameters; $G_{m o}$ is the initial shear modulus; $\gamma_{r}$ is the reference shear strain; $b$ is the correction coefficient of $\gamma_{r}$ at different depth; $\sigma^{\prime}$ is the effective vertical stress; $\sigma_{r e f}$ is the reference effective vertical stress at which $\gamma_{r}$ is equal to $\gamma_{\text {ref }}$.
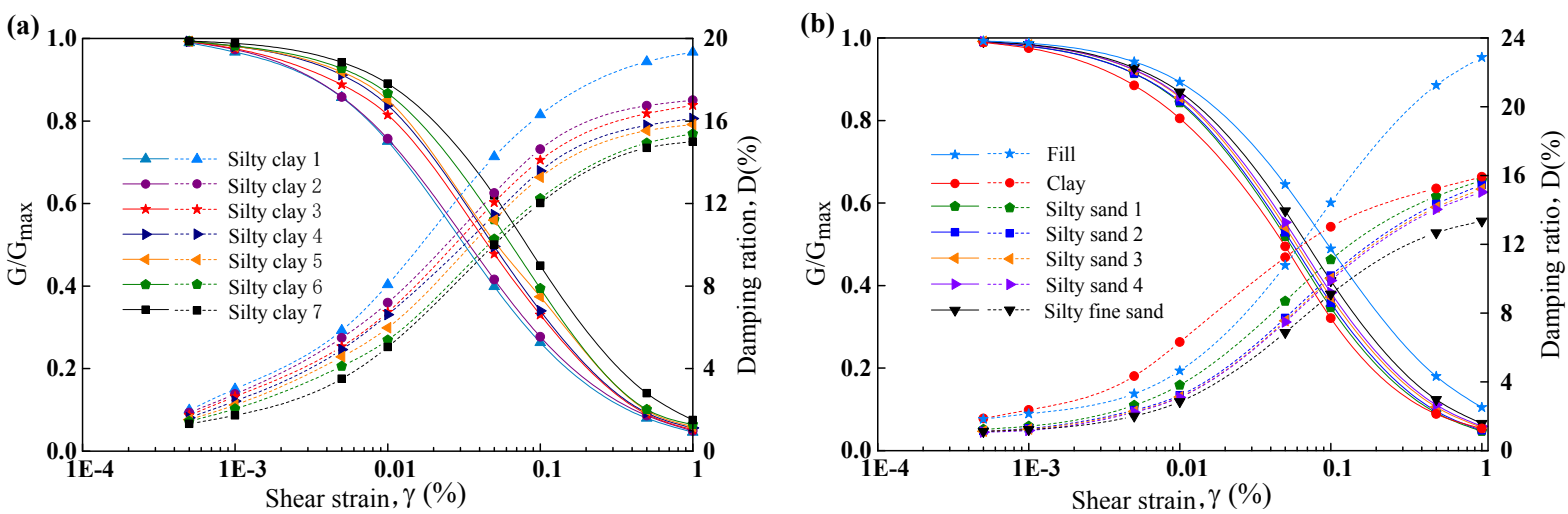

Figure 2: G/Gmax and damping ratio D curves versus shear strain amplitude $\gamma$ for soils in Suzhou region: (a) Silty clay; (b) Fill, Clay, Silty sand and Silty fine sand.

According to the borehole data, as well as the resonant column test results for typical soil samples of depth less than $100 \mathrm{~m}$ in Suzhou, Figure 2 shows the normalized shear modulus degradation and damping ratio curves as functions of the shear strain. The nonlinear behavior of soil decreases with increasing depth, namely, shallow soils are more nonlinear than deep soils. Moreover, the damping ratio of soil increases with increasing shear strain. The damping ratio is very small at small strain. In DEEPSOIL, the model parameters can be determined by fitting the inputted modulus-reduction and damping curves. For soils of depth less than $100 \mathrm{~m}$, due to the layers are thin, the shear modulus degradation and damping ratio curves are directly given by laboratory experiments. However, for silty fine sand, silty clay 7 and silty sand 4 of depth more than $100 \mathrm{~m}$, the corresponding curves are given by the correction method considering the effect of confining pressure. The correction coefficient $b$ is equal to 0.5 for silty fine sand and silty sand 4, and 0.5 for silty clay 7 [12]. In nonlinear analysis, the thickness of the layer $i$ is determined by the maximum frequency that can be propagated:

$$
h_{i}=\frac{\left(v_{s}\right)_{i}}{4 f_{\max }}
$$

Where $h_{i}$ is the thickness of each layer, $\left(v_{s}\right)_{i}$ is the shear wave velocity, $f_{\max }$ is the maximum frequency that the layer $i$ can propagate. Generally, for all layers, the maximum frequency should be of $25-50 \mathrm{~Hz}$, therefore, the thickness of each layer was of 1-4 m. An elastic bedrock was taken as the seismic bedrock interface of input motions, and the Rayleigh damping at 2nd modes was employed as viscous damping. To ensure the calculation results have high accuracy, the number of iterations was selected as 20 in equivalent linear analysis, while in nonline- 
ar analysis, the flexible sub-incrementation scheme with $\Delta \gamma_{\max }=10^{-6}$ was used to control increment step. In addition, the interface of elastic homogeneous bedrock and nonhomogeneous soil is taken as the seismic bedrock interface of input motion. However, the depth of seismic bedrock interface has a significant effect on design ground motion parameters. Hence, for deep site in Suzhou region, the soil layer with shear velocity not less than $700 \mathrm{~m} / \mathrm{s}$ was selected as the seismic bedrock interface [13].

\section{SELECTION OF INPUT EARTHQUAKE RECORDS}

Many studies have shown that bedrock motion characteristics have an important impact on the seismic site response. Therefore, in this paper, a suite of three horizontal acceleration records were selected as the bedrock motion to cover a wide range of amplitudes, frequency contents, and durations, including the ground motion records on Montebello-Bluff site during the 1994 Ms 6.7 Northridge earthquake in America, Feltre site during the 1976 Ms 6.5 Friuli earthquake in Italy, and Jingning site during the $2008 \mathrm{Ms} 8.0$ Wenchuan earthquake in china. The intensity of bedrock motion is characterized by peak ground acceleration (PGA) and Arias intensity (AI) [14]; the frequency content is characterized by predominant period $\left(T_{\mathrm{p}}\right)$, and the duration is characterized by significant duration between $5 \%$ and $95 \%$ of the AI $\left(D_{5-95}\right)$. These main characteristics of input ground motions are summarized in Table 1. The acceleration time histories and Fourier spectra of bedrock motions are shown in Figure 3. The cumulative energy curves of bedrock motions in frequency domain are shown in Figure 4 . In the Montebello -Bluff Rd record, $90 \%$ of the energy is present in a narrower frequency band $(0.1$ $4.9 \mathrm{~Hz}$ ). in the Feltre record, the mid- and high-frequency components are abundant, $90 \%$ of the energy is present in the frequency band of $0.2-13.8 \mathrm{~Hz}$. In addition, the energy cumulated in the frequency band of $10.0-13.8 \mathrm{~Hz}$ is as much as $45 \%$ of the total energy. However, in the

Table 1: Details of input ground motions used for site response analysis.

\begin{tabular}{|c|c|c|c|c|c|c|c|c|c|}
\hline Event (Year) & Ms & Station name & $\begin{array}{c}\text { Epicentral } \\
\text { distance } \\
(\mathrm{km})\end{array}$ & Component & $\begin{array}{c}\text { PGA } \\
(\mathrm{g})\end{array}$ & $\begin{array}{c}\mathrm{AI} \\
(\mathrm{m} / \mathrm{s})\end{array}$ & $\begin{array}{l}T_{\mathrm{p}} \\
(\mathrm{s})\end{array}$ & $\begin{array}{l}\mathrm{D}_{5-95} \\
\text { (s) }\end{array}$ & $\begin{array}{l}\text { Sample rate } \\
(\mathrm{Hz})\end{array}$ \\
\hline Northridge (1994) & 6.7 & $\begin{array}{c}\text { Montebello- } \\
\text { Bluff Rd }\end{array}$ & 46.21 & S26W & 0.179 & 0.323 & 0.24 & 10.58 & 100 \\
\hline Friuli (1976) & 6.5 & Feltre & 108.56 & EW & 0.038 & 0.014 & 0.08 & 12.34 & 200 \\
\hline Wenchuan (2008) & 8.0 & Jingning & 552 & EW & 0.025 & 0.021 & 0.7 & 33.02 & 200 \\
\hline
\end{tabular}
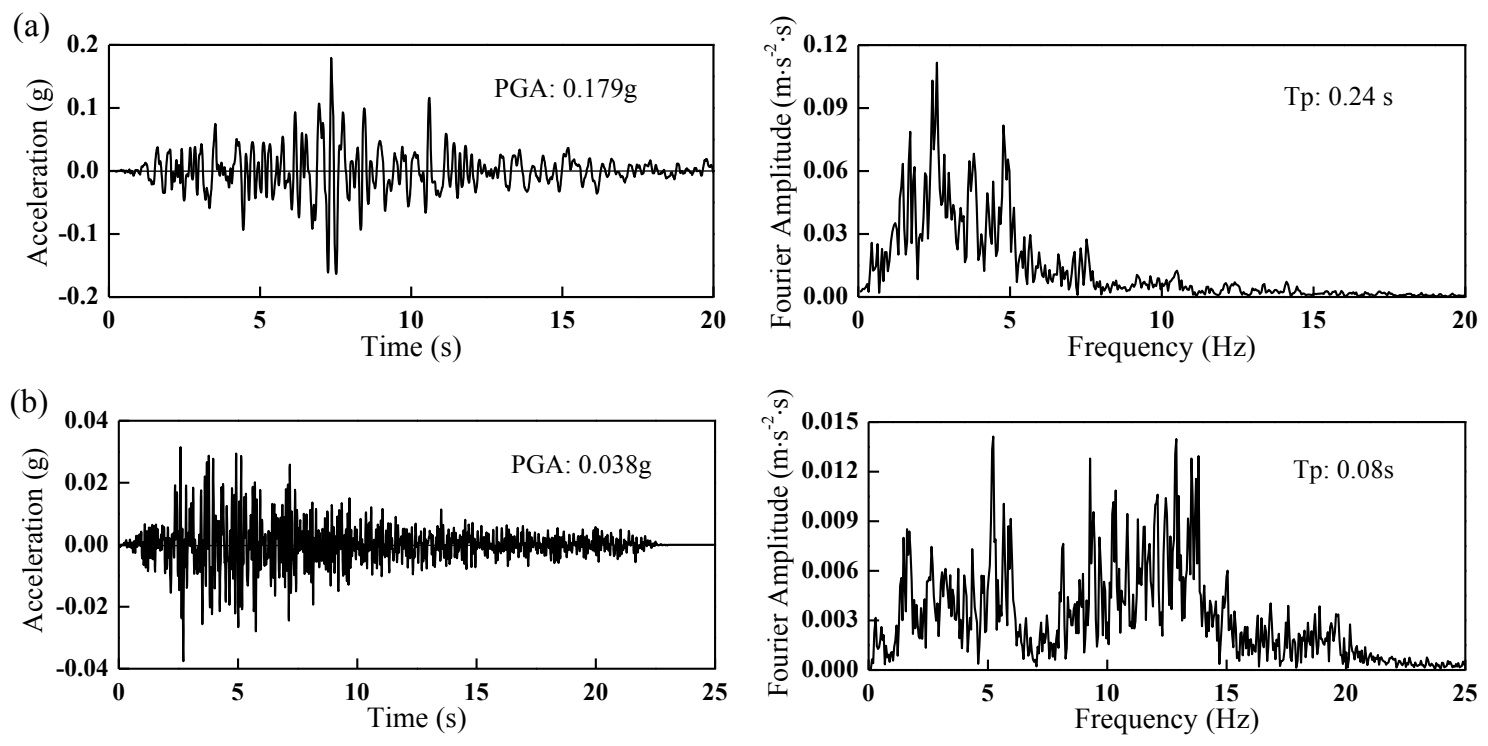

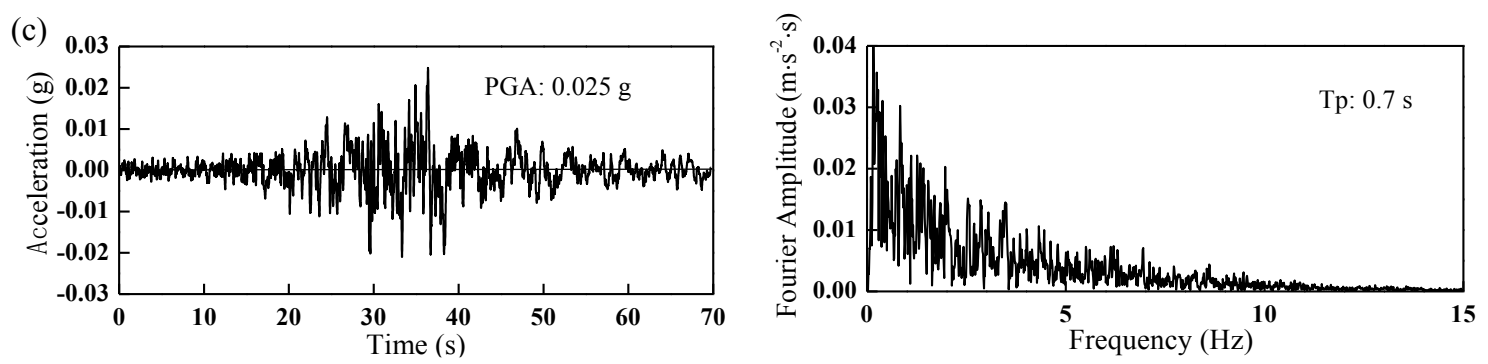

Figure 3: Time histories of acceleration and Fourier spectra of bedrock motions: (a) Montebello-Bluff Rd record; (b) Feltre record and (c) Jingning record.

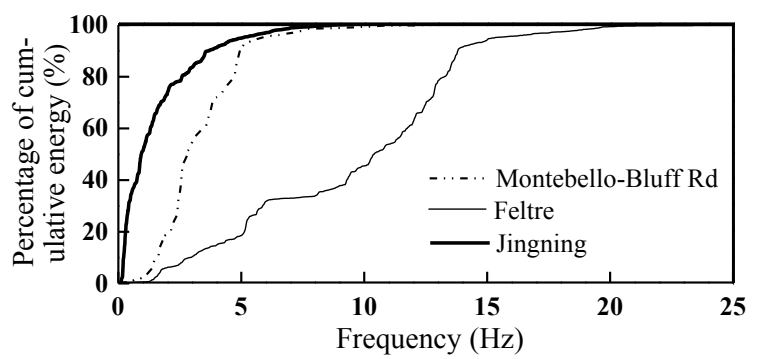

Figure 4: Cumulative energies of bedrock motions in frequency domain

Jingning record, the low frequency component is extremely abundant, $90 \%$ of the energy is present in the narrower frequency band $(0.1-3.8 \mathrm{~Hz})$, and the energy cumulated in the frequency band of $0.1-0.9 \mathrm{~Hz}$ is as much as $50 \%$ of the total energy.

\section{SITE RESPONSE ANALYSIS RESULTS}

In what follows, we study the effect of input motion in terms of intensity and frequency content on the resulting surface ground motion. To model different levels of intensity, the PGA values of the seismic records were adjusted to $0.01,0.025,0.05,0.10,0.15,0.20,0.25$ and $0.3 \mathrm{~g}$, respectively. Input motions with PGA $\leqslant 0.05 \mathrm{~g}, \mathrm{PGA}=0.10-0.20 \mathrm{~g}, \mathrm{PGA} \geqslant 0.25 \mathrm{~g}$ are defined as low-level earthquakes, moderate-level earthquakes, high-level earthquakes, respectively. We perform equivalent linear frequency domain site response analyses (ELA) and nonlinear time domain site response analyses (NLA) using DEEPSOIL.

\subsection{Peak shear strain}

Figure 5 shows the variations of peak shear strain $\gamma_{\max }$ with soil depth for borehole profile No. 1 calculated by ELA and NLA under bedrock motions of Montebello-Bluff Rd record and Feltre record with different intensities. Bedrock motion characteristics and site response analysis methods have significant effect on $\gamma_{\max }$, however, the maximum values of $\gamma_{\max }$ are approximately presented at the same depth. The depth is approximately $9.5 \mathrm{~m}$. The $\gamma_{\max }$ at depth of $9.5 \mathrm{~m}$ for borehole profile No.1 under different bedrock motions are shown in figure 6. It can be seen that the $\gamma_{\max }$ values of shallow soils computed using ELA and NLA are significantly different, and this difference increases with the increase of bedrock motion intensity. When the bedrock PGA is less than or equal to $0.05 \mathrm{~g}$, the $\gamma_{\max }$ values of shallow soils, which just reach the order of $10^{-4}$ only in a few cases, are almost in the order of $10^{-5}$. The $\gamma_{\max }$ values calculated by ELA are close to those calculated by NLA, the state of soil is in nonlinear elastic range or just reaches nonlinear range. When the bedrock PGA is between $0.1 \mathrm{~g}$ and $0.2 \mathrm{~g}$, the $\gamma_{\max }$ values of shallow soils are in the order of $10^{-4}$ under Feltre record with abundant high frequency, the state of soil is in nonlinear range; however, the corresponding $\gamma_{\max }$ values reach the order of $10^{-3}$ under Jingning record with abundant low frequency, the soils exhibit strong 
nonlinearity. In this case, seismic site response under low frequency earthquake is much larger than that under high frequency earthquake. When the bedrock PGA is more than or equal to $0.25 \mathrm{~g}$, the $\gamma_{\max }$ values of shallow soils are all in the order of $10^{-3}$ under different bedrock motions, the soils exhibit strong nonlinearity. Moreover, the difference between $\gamma_{\max }$ values calculated by ELA and NLA is significant.
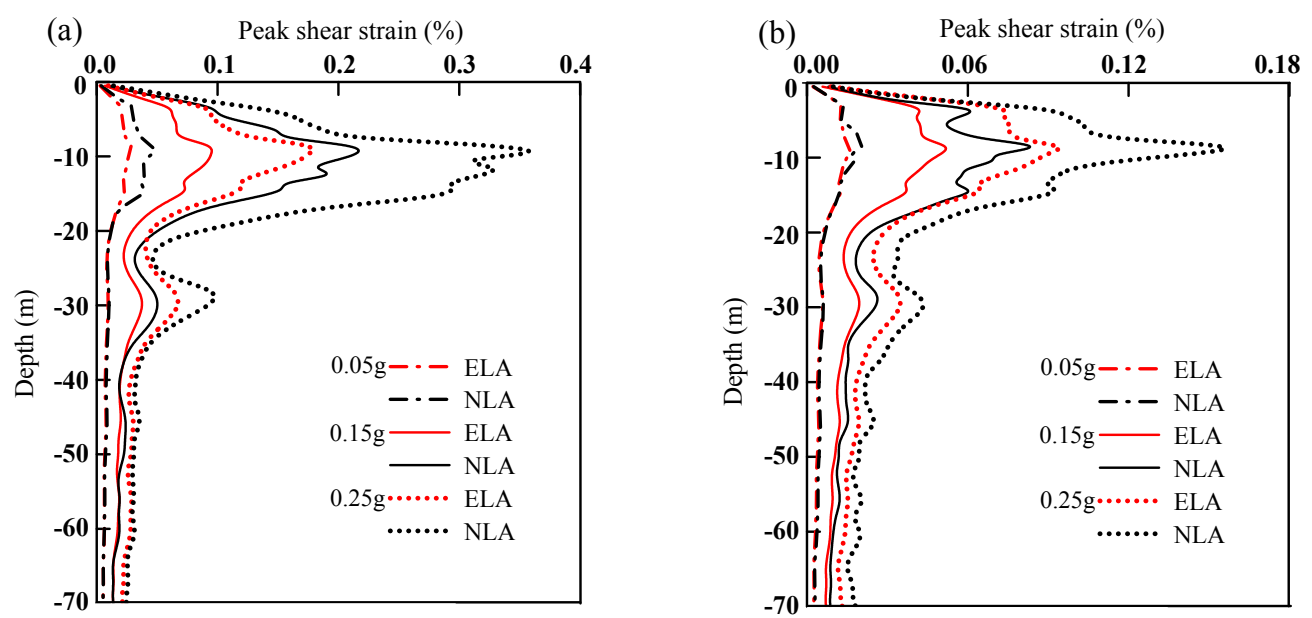

Figure 5: Variation of peak shear strain with soil depth for borehole profile No. 1 under different input motions with PGA=0.05g, 0.15g and 0.25g: (a) Montebello-Bluff Rd record and (b) Feltre record.

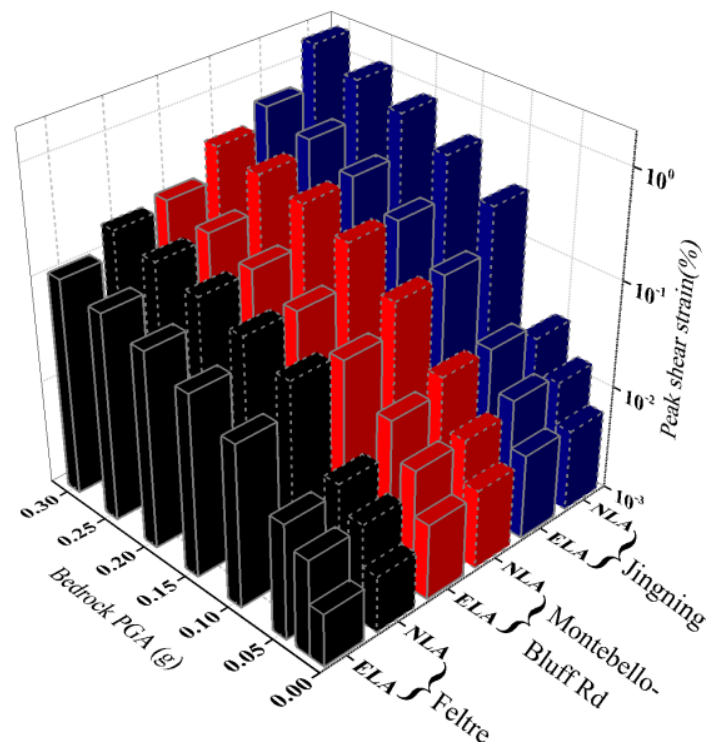

Figure 6: Peak shear strain at depth of $9.5 \mathrm{~m}$ for borehole profile No. 1 under bedrock motions with different intensities and frequency spectrum characteristics

\subsection{Effect of bedrock motion intensities on surface PGAs}

The surface PGAs of borehole profiles No. 1 and 2 under different seismic bedrock motion levels calculated by ELA and NLA are shown in figure 7(a) and (b), respectively. Surface PGAs calculated by ELA increase monotonically as the PGAs of bedrock motion increase. However, surface PGAs calculated by NLA first increase rapidly and then decrease gradually or keep constant. When the bedrock PGA is equal or lesser than $0.05 \mathrm{~g}$, the soil layer is approximately linear elastic, and thus the surface PGAs given by the two methods are very close. When the bedrock PGA is between $0.1 \mathrm{~g}$ and $0.2 \mathrm{~g}$, the nonlinear effect of soil layer is remarkable. Accordingly, surface PGAs computed by ELA and NLA are significantly different, the 
surface PGAs in NLA are much greater than those in ELA. However, the surface PGAs given by the two methods both increase with the increase of bedrock PGAs. In addition, surface PGAs are closely related to the spectral characteristics of bedrock ground motions. Specifically, the more abundant the low frequency contents of bedrock ground motions are, the larger the surface PGAs are. However, the difference between surface PGAs calculated by ELA and NLA increases as the high frequency contents of bedrock ground motions become richer. Namely, the difference is the largest when inputting the Feltre record with rich high frequency contents, which is followed successively by inputting Montebello-Bluff $\mathrm{Rd}$ record and Jingning record with rich low frequency contents. When the bedrock PGA is larger than or equal to $0.25 \mathrm{~g}$, the shallow soil layer shows strong nonlinearity. The nonlinear constitutive model can reflect the yield of the soil at large strain level $\left(>10^{-3}\right)$. In this condition, the surface PGAs given by NLA are close to or even smaller than those given by ELA. The deep sediment layers have significant high-frequency contents filtering and low frequency contents amplification effects on bedrock ground motions. As the transient tangent stiffness of soil is greater than the secant stiffness of soil in strong nonlinearity range, the high frequency contents of bedrock ground motions given by NLA are amplified. In other words, the nonlinear seismic effect of deep layer during large earthquake is a comprehensive reflection of these two effects.
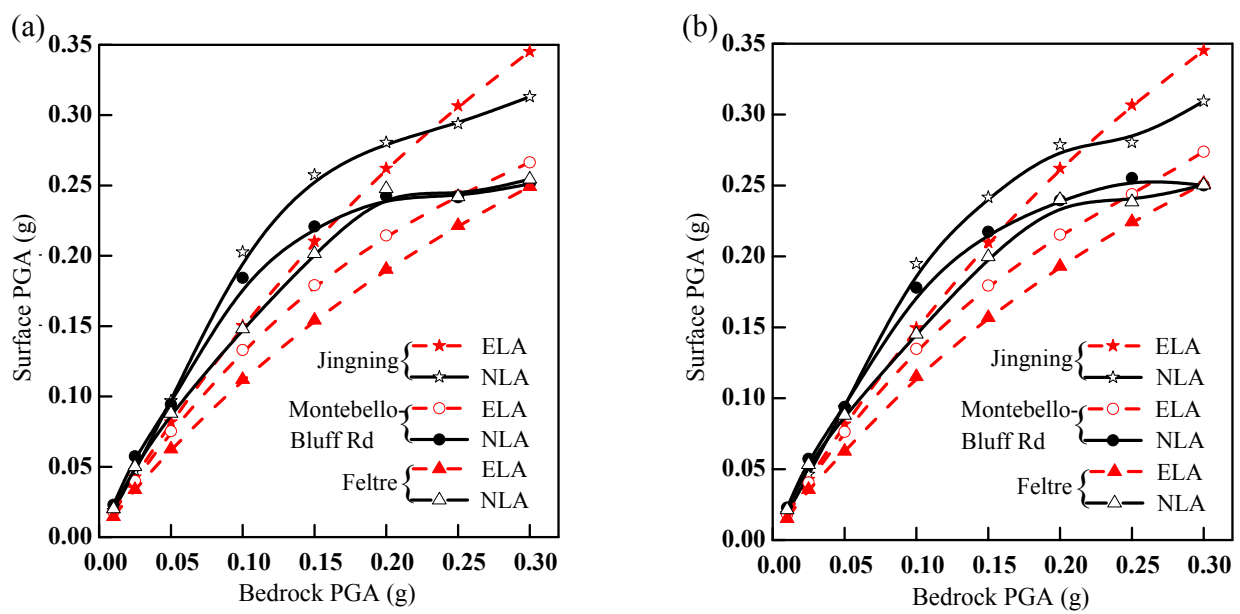

Figure 7: Effect of bedrock motion intensities on PGAs at the surface of: (a) borehole profile No. 1 and (b) borehole profile No. 2

\subsection{Effect of bedrock motion characteristics on surface spectral acceleration}

Figure 8 shows the surface Sa spectra of borehole profile No. 1 under bedrock motions of Feltre record and Jingning record. Compared with the bedrock Sa spectra, the amplification effect of surface Sa spectra at short periods computed using ELA reduces significantly as the PGAs of bedrock motions increase, and the predominant periods move to long periods. Thus, during low-level earthquakes with PGAs equal to 0.01 and $0.05 \mathrm{~g}$, moderate-level earthquakes with PGA equal to $0.15 \mathrm{~g}$, and high-level earthquakes with PGA equal to $0.3 \mathrm{~g}$, the predominant periods of surface ground motions are $0.08 \mathrm{~s}, 0.19 \mathrm{~s}, 0.19 \mathrm{~s}$, and $0.63 \mathrm{~s}$ for Feltre record, respectively; and the corresponding predominant periods are $0.34 \mathrm{~s}, 0.7 \mathrm{~s}, 0.7 \mathrm{~s}$ and $1.22 \mathrm{~s}$ for Jingning record. It is obvious that the long period components of ground motions become richer and the high frequency components are filtered out. Although the spectrum shapes of Sa computed by NLA exhibit different trend, but the corresponding predominant periods are roughly identical to those computed by ELA. In NLA, the high frequency components first magnify and then attenuate as the PGAs of bedrock motion increase. When the bedrock PGA 
is equal or lesser than $0.05 \mathrm{~g}$, the $\gamma_{\max }$ values of soils are in the order of $10^{-5}-10^{-4}$. Thus, the soils exhibit nonlinear elastic behavior, and the different frequency components of ground motions have different amplifications. In general, the spectrum shapes of surface Sa given by the two methods are the similar in a wide period range, however, the Sa values computed by NLA in the short period range of $\mathrm{T}<0.5 \mathrm{~s}$ are larger than those computed by NLA. When the intensity of input ground motion increases, such as the input PGA=0.15 g, the $\gamma_{\max }$ values of soils are approximately in the order of $10^{-4}-10^{-3}$. Thus, the strong nonlinearity of soils has significant filtering effect on the high frequency components of ground motion. The surface Sa spectra computed by ELA are smaller than the bedrock Sa spectra in the short period range
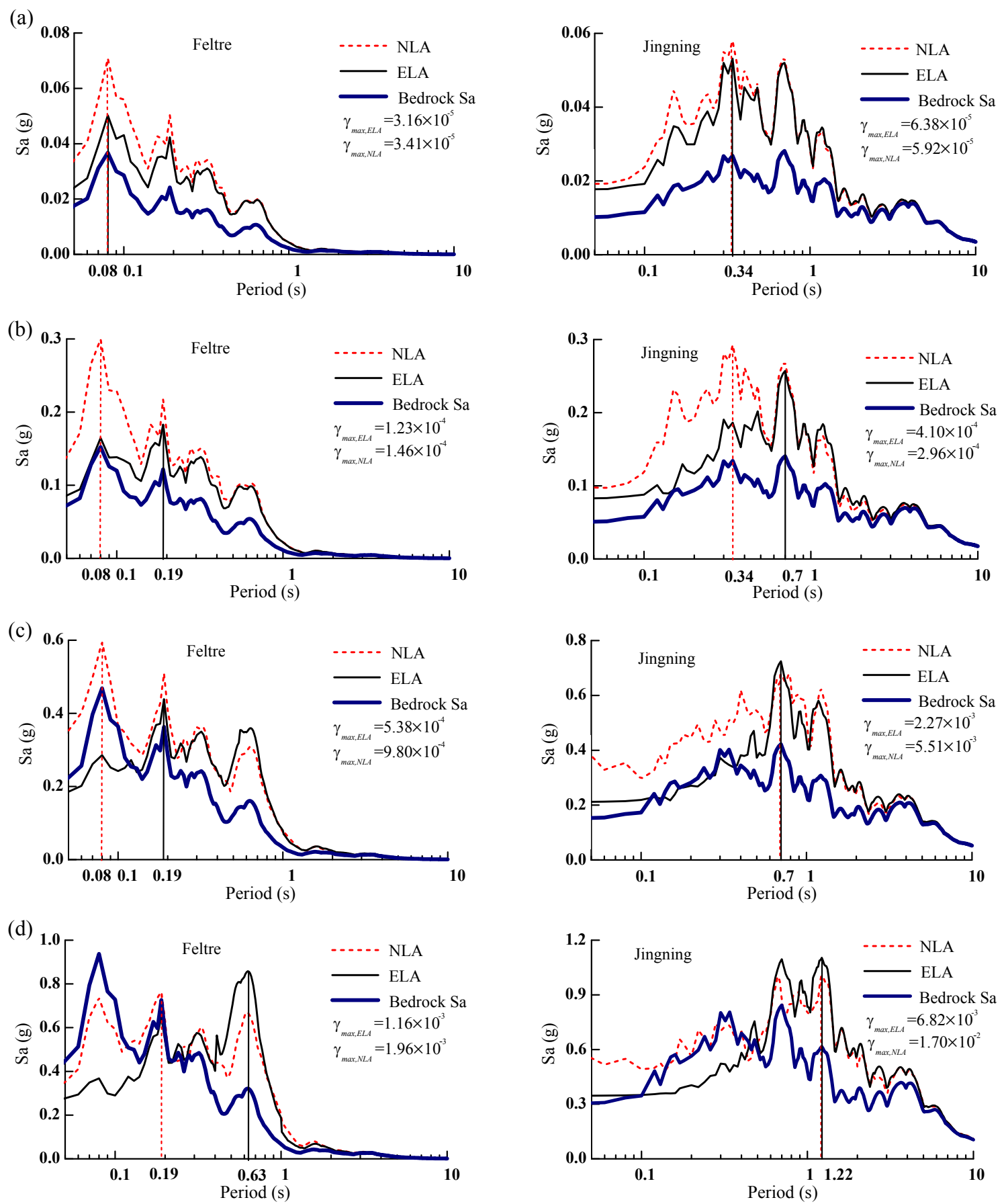

Figure 8: Surface acceleration response spectra under bedrock motions with different intensities for borehole profile No.1: (a) PGA $=0.01 \mathrm{~g}$; (b) $\mathrm{PGA}=0.05 \mathrm{~g}$; (c) $\mathrm{PGA}=0.15 \mathrm{~g}$ and (d) $\mathrm{PGA}=0.3 \mathrm{~g}$ 
of $\mathrm{T}<0.12 \mathrm{~s}$. In general, the surface Sa spectra computed by NLA are larger than those computed by ELA in a wide period range. However, at the period of approximate $0.6 \mathrm{~s}$, the surface Sa spectra computed by ELA are larger than those computed by NLA. When the bedrock PGA is $0.3 \mathrm{~g}$, the $\gamma_{\max }$ values of soils are in the order of $10^{-3}-10^{-2}$. The shallow soils exhibit strong nonlinearity. Therefore, the high frequency components of the ground motion are greatly filtered, and the long period components are significantly amplified. Compared with the bedrock spectra, the surface Sa spectra at middle and long periods exhibit different magnification effects.

\subsection{Duration of ground motion}

Ground motion duration is an important parameter to characterize the ground motion. The prolongation of duration will increase the cumulative deformation of the structure, or even result in the loss of local structural strength due to low cycle fatigue [15]. Figure 13 shows the ground motion duration prolongation values $\Delta D_{5-95}$ for borehole profile No. 1 calculated by ELA and NLA under different seismic bedrock motions. The value is defined as:

$$
\Delta D_{5-95}=D_{5-95, \text { surf }}-D_{5-95, \text { bedr }}
$$

Where $\Delta D_{5-95, \text { surf }}$ and $\Delta D_{5-95, \text { bedr }}$ are the durations of surface and bedrock ground motions between the 5\% and $95 \%$ Arias intensity, respectively.

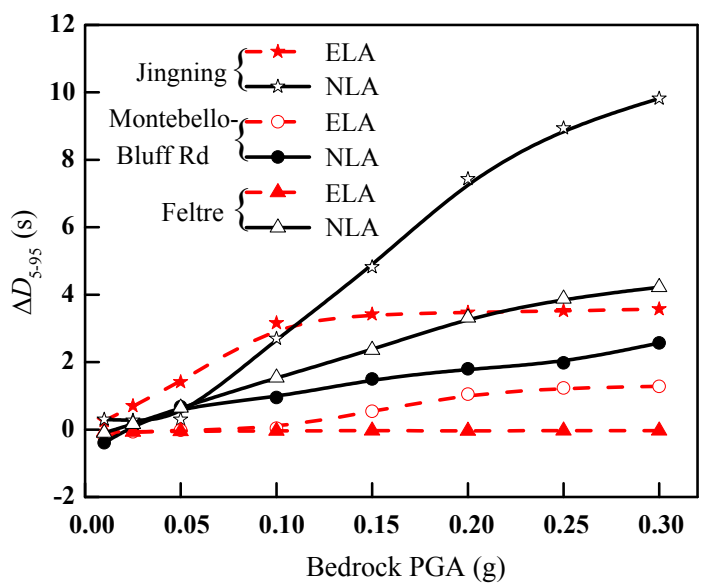

Figure 9: Prolongations of the ground motion duration for standard profile No. 1

The ground motion duration is not only related to the characteristics of bedrock motion [16], but also closely related to seismic site response analysis methods. And these correlations are enhanced with the increase of bedrock motion intensity. When the bedrock PGA is more than $0.05 \mathrm{~g}$, the $\Delta D_{5-95}$ values calculated by ELA are the largest when inputting Jingning record, which are followed successively by inputting Montebello-Bluff Rd record and Feltre record. The $\Delta D_{5-95}$ values calculated by NLA are also the largest when inputting Jingning record, however, followed successively by inputting Feltre record and Montebello-Bluff Rd record. This may be because the energy of Feltre record is mainly concentrated in high frequency band, and the energy in this frequency band will be filtered out by using ELA method. Therefore, when the Feltre record is inputted as bedrock motion, the durations of surface ground motion calculated by ELA are even reduced, that is, the $\Delta D_{5-95}$ values are negative. In addition, with the increase of the bedrock motion intensity, the $\Delta D_{5-95}$ values given by ELA increase rapidly to a value that is basically constant; however, the corresponding $\Delta D_{5-95}$ values given by NLA continue to increase, while the gradients decrease gradually. 


\section{CONCLUSIONS}

Based on typical borehole profiles in Suzhou region, the seismic site responses in deep sediment layers are performed and compared by ELA and NLA methods. The conclusions are as follows:

1. The surface PGAs calculated by ELA increase monotonically with the increase of bedrock motion intensity. However, the surface PGAs calculated by NLA first increase rapidly and then decrease gradually or keep constant. In addition, the surface PGA is closely related to the spectral components of the bedrock ground motion, and the difference between surface PGAs computed by ELA and NLA increases as the high frequency components of the bedrock ground motions become richer.

2. As the intensity of bedrock motion increases, the amplification effect of surface Sa spectra at short periods computed using ELA reduces significantly, and the predominant periods move to long periods. However, the spectrum shapes of surface Sa spectra computed by NLA exhibit different trend. Specifically, the high frequency components of bedrock motions first magnify and then attenuate.

3. The surface ground motion duration is not only related to the characteristics of bedrock motion, but also closely related to the cyclic behavior of nonlinear soil medium. And these correlations increase with the increase of bedrock motion intensity. Generally, the influence of bedrock motion intensity on the duration prolongation of surface ground motion can be reasonably evaluated using NLA.

\section{REFERENCES}

[1] S.E. Hough, J.R. Altidor, D. Anglade, D. Given, M.G. Janvier, J.Z. Maharrey, M. Meremonte, B.S.-L. Mildor, C. Prepetit, A. Yong, Localized damage caused by topographic amplification during the 2010 M 7.0 Haiti earthquake. Nature Geoscience, 3, 778-782, 2010.

[2] G. Lanzo, F. Silvestri, A. Costanzo, A. d'Onofrio, L. Martelli, A. Pagliaroli, S. Sica, A. Simonelli, Site response studies and seismic microzoning in the Middle Aterno valley (L'aquila, Central Italy). Bulletin of Earthquake Engineering, 9, 1417-1442, 2011.

[3] G.X. Chen, J.Y. Zhan, J.D. Liu, X.J. Li, Parameter study on ground motion design of deep soft site under far-field large earthquake. Chinese Journal of Geotechnical Engineering, 35, 1591-1599, 2013.

[4] H.B. Seed, I.M. Idriss, Soil moduli and damping factors for dynamic response analyses. Report No. EERC 70-10, University of California, Berkeley, 1970.

[5] T. Satoh, M. Horike, Y. Takeuchi, T. Uetake, H. Suzuki, Nonlinear behaviour of scoria soil sediments evaluated from borehole records in eastern Shizuoka prefecture, Japan. Earthquake Engineering \& Structural Dynamics, 26, 781-795, 1997.

[6] C. Gélis, L.F. Bonilla, Influence of a sedimentary basin infilling description on the 2-D P-SV wave propagation using linear and non-linear constitutive models. Geophysical Journal International, 198, 1684-1700, 2014.

[7] C. Bolisetti, A.S. Whittaker, H.B. Mason, I. Almufti, M. Willford, Equivalent linear and nonlinear site response analysis for design and risk assessment of safety-related nuclear structures. Nuclear Engineering and Design, 275, 107-121, 2014. 
[8] J. Kaklamanos, L.G. Baise, E.M. Thompson, L. Dorfmann, Comparison of 1D linear, equivalent-linear, and nonlinear site response models at six KiK-net validation sites. Soil Dynamics and Earthquake Engineering, 69, 207-219, 2015.

[9] Chinese Standard, Code for Seismic Design of Buildings issued by Ministry of Housing and Urban-Rural Development of the People's Republic of China, Beijing, GB500112010, 19-20, 2010.

[10] Y.M.A. Hashash, D. Park, Non-linear one-dimensional seismic ground motion propagation in the Mississippi embayment. Engineering Geology, 62, 185-206, 2001.

[11] Y.M.A. Hashash, M.I. Musgrove, J.A. Harmon, D.R. Groholski, C.A. Phillips, D. Park, DEEPSOIL 6.1, User Manual, 2016.

[12] T. Jiang, H.L. Xing, A simple method considering effects of confining pressure on dynamic shear moduli and damping ratio. Chinese Journal of Rock Mechanics and Engineering, 26, 1432-1437, 2007.

[13] J. Zhu, G.X. Chen, H.G. Xu, Effect of seismic bedrock interface depth on surface motion parameters of deep site. Chinese Journal of Geotechnical Engineering, 37, 20792087, 2015.

[14] A. Arias, A measure of earthquake intensity. Seismic Design for Nuclear Power Plants, R. J. Hansen(Editor), MIT Press, Cambridge, Massachusetts, 438-483, 1970.

[15] J. Hancock, J.J. Bommer, Using spectral matched records to explore the influence of strong-motion duration on inelastic structural response. Soil Dynamics and Earthquake Engineering, 27, 291-299, 2007.

[16] G.X. Chen, D.D. Jin, J. Zhu, J. Shi, X.J. Li, Nonlinear analysis on seismic site response of Fuzhou Basin, China. Bulletin of the Seismological Society of America, 105, 928-949, 2015. 